\title{
Association between Foot Posture Index and Ankle Sprain in Indoor Football Players
}

\author{
Afsaneh Safar Cherati ${ }^{1}$, Masoud Dousti ${ }^{2} \&$ Shima Younespour ${ }^{3}$ \\ ${ }^{1}$ Sports Medicine Research Center, Tehran University of Medical Sciences, Tehran, Iran \\ ${ }^{2}$ Rasoul Akram Hospital, Iran University of Medical Science, Tehran, Iran \\ ${ }^{3}$ School of Public Health, Tehran University of Medical Sciences, Iran \\ Correspondence: Masoud Dousti, Rasoul Akram Hospital, Iran University of Medical Science, Tehran, Iran. Tel: \\ 98-912-772-2071. E-mail: Dr_masoud_dousti@yahoo.com
}

Received: July 26, 2015 Accepted: August 20, 2015 Online Published: February 24, 2016

doi:10.5539/gjhs.v8n10p160 URL: http://dx.doi.org/10.5539/gjhs.v8n10p160

\begin{abstract}
Objective: This study investigated the relationship between foot type and ankle sprain incidence.

Method: In a prospective cohort study using the FPI, 68 adult male and female indoor football (Futsal) players were measured and their feet were classified according to foot posture index (FPI) as neutral, supinated and pronated. They were followed over 6 month as a one competition season and at the end, any injuries at the ankle during this period were detected.

Result: There was no significant association between FPI score (considering the total FPI score and its six components) and occurrence of ankle sprain. Also, no association was existed between gender, age, height, weight, BMI, duration of professional exercise, dominant foot and occurrence of ankle sprain. In this study, the history of previous ankle sprain was the only significant predictor of the occurrence of ankle sprain in the follow-up period. Participants with the positive history of previous ankle sprain were at higher risk of developing new ankle sprain $(\mathrm{OR}=6.02,95 \% \mathrm{CI}$ : $(1.93,18.84), \mathrm{p}=0.002)$.
\end{abstract}

Conclusion: There was no significant association between FPI score and occurrence of ankle sprain.

Limitation: There was scarce of supinated foot in the study so evaluation of relationship between supinated feet and ankle sprain was not applicable.

Keywords: foot posture index, ankle sprain, indoor football player

\section{Introduction}

Due to prevalence of ankle ligament injury in football players, this athlete group may face various biomechanical, functional and financial hazards. The underlying pathophysiology is not completely understood and several mechanism have been spotted in development of it (Canale \& Beaty, 2008; DiGiovanni \& Greisberg, 2007). Indoor Football is a sport characterized by repetitive, short duration, high intensity bursts of activity with abrupt change of direction. Therefore, Lateral ankle sprain caused by inversion trauma as the most prevalent acute injury, can occur following a career in the field. A distinctive constellation of extrinsic and intrinsic factors are responsible for the damage (Chinn \& Hertel, 2010; Kaufman, Brodine, Shaffer, Johnson, \& Cullison, 1999). Alteration in ligamentous laxity, muscular strength, anatomic foot and ankle alignment, postural sway, gait biomechanics, and muscle reaction time may be observed as potential intrinsic risk factors for dysfunction (Cote, Brunet, II, \& Shultz, 2005; Hertel, 2000; McManus et al., 2004; Urguden et al., 2011). low medial longitudinal arch could present as an isolated biomechanical derangement sustained a higher percentage of lateral ankle sprain (Mei-Dan et al., 2005). Moreover, some authors reported high incidence of this injury in females with an increased calcaneal eversion range of motion (Beynnon, Murphy, \& Alosa, 2002). In a literature review, relationship between foot characteristics and inversion ankle injury was studied. It has been demonstrated that increased foot width, cavovarus deformity and increased calcaneal eversion range of motion are static foot characteristics that have a distinct correlation with lateral ankle sprain (Morrison \& Kaminski, 2007).

Furthermore, a six-item criterion reference tool, the Foot Posture Index has demonstrated high validity in evaluation of rearfoot, midfoot and forefoot charactristics (Redmond, Crane, \& Menz, 2008; Redmond, Crosbie, 
\& Ouvrier, 2006). Each section could be subject of deformity or malalignment.

Hence, based on the available evidences, each of the pointed disturbances may be observed in this injury. However, different studies have been reported in the literature especially regarding the dynamic and static alignment and posture (Burns, Keenan, \& Redmond, 2005; Willems, Witvrouw, Delbaere, De Cock, \& De Clercq, 2005). Considering the athlete's demographic and epidemiologic difference, the present study was conducted to demonstrate correlation between static characteristics of foot and ankle alignment with ankle sprain injury in Iranian Futsal player.

\section{Materials \& Methods}

\subsection{Study Subjects}

For this prospective cohort study, a total of 68 adolescent male and female indoor football (Futsal) players of Iranian premier league participated in the study. Their feet were classified according to foot posture index (FPI) as neutral, supinated and pronated. (Figure 1, Figure 2) Then they followed monthly over one competition season during 6 months.

Subjects' baseline characteristics including demographic parameters, past history of ankle sprain and duration of professional sports were recorded by interviewing. The institutional research ethics committee approved the study and all participants were informed the details of the study and also about the possible hazards of the study.

\subsection{Study Measurements}

At first, a pilot study consisting of 15 subjects conducted in sports medicine clinic. Intra-rater reliability of measurements were confirmed ( $\mathrm{ICC}=92$ ). All measurements been performed by one physician.

Height was measured by stadiometer, to $0.5 \mathrm{~cm}$, weight by electronic scale, to $0.1 \mathrm{~kg}$, and BMI was calculated.

Participants' feet were evaluated by six-item criterion reference tool, the Foot Posture Index (FPI), scored and were classified as neutral, supinated and pronated (Redmond et al., 2008; Redmond et al., 2006) whereas positive scores are consistent with pronation and negative scores are indicative of supination. (Table 1)

Table 1. Results of GEE analysis to examine the association between FPI components and occurrence of new ankle sprain

\begin{tabular}{|c|c|c|c|c|c|c|c|c|}
\hline \multirow[b]{2}{*}{ Components of FPI score } & \multicolumn{5}{|c|}{ Score $^{\#}$} & \multicolumn{2}{|c|}{ OR $(95 \%$ CI for OR)* } & \multirow[b]{2}{*}{$\mathrm{P}$} \\
\hline & -2 & -1 & 0 & +1 & +2 & $\begin{array}{l}\text { Slightly } \\
\text { pronated (vs. } \\
\text { Neutral) }\end{array}$ & $\begin{array}{l}\text { Severely } \\
\text { pronated (vs. } \\
\text { Neutral) }\end{array}$ & \\
\hline Talar head palpation & & & & & & $1.23(0.29,5.25)$ & $1.19(0.25,5.75)$ & 0.96 \\
\hline Right foot & - & - & $\begin{array}{l}9 \\
(13.2 \%)\end{array}$ & $\begin{array}{l}37 \\
(54.4 \%)\end{array}$ & $\begin{array}{l}22 \\
(32.4 \%)\end{array}$ & & & \\
\hline Left foot & - & - & $\begin{array}{l}11 \\
(16.2 \%)\end{array}$ & $\begin{array}{l}37 \\
(54.4 \%)\end{array}$ & $\begin{array}{l}20 \\
(29.4 \%)\end{array}$ & & & \\
\hline $\begin{array}{l}\text { Supra and infra lateral } \\
\text { malleolar curvature }\end{array}$ & & & & & & $1.87(0.70,4.99)$ & $3.92(0.76,20.25)$ & 0.21 \\
\hline Right foot & - & $\begin{array}{l}1 \\
(1.5 \%)\end{array}$ & $\begin{array}{l}31 \\
(45.6 \%)\end{array}$ & $\begin{array}{l}29 \\
(42.6 \%)\end{array}$ & $\begin{array}{l}7 \\
(10.3 \%)\end{array}$ & & & \\
\hline Left foot & - & $\begin{array}{l}1 \\
(1.5 \%)\end{array}$ & $\begin{array}{l}30 \\
(44.1 \%)\end{array}$ & $\begin{array}{l}32 \\
(47.1 \%)\end{array}$ & $5(7.4 \%)$ & & & \\
\hline $\begin{array}{l}\text { Calcaneal frontal plane } \\
\text { position }\end{array}$ & & & & & & $1.39(0.50,3.81)$ & $1.99(0.33,12.18)$ & 0.71 \\
\hline Right foot & - & - & $\begin{array}{l}21 \\
(30.9 \%)\end{array}$ & $\begin{array}{l}41 \\
(60.3 \%)\end{array}$ & $6(8.8 \%)$ & & & \\
\hline Left foot & - & - & $\begin{array}{l}24 \\
(35.3 \%)\end{array}$ & $\begin{array}{l}37 \\
(54.4 \%)\end{array}$ & $\begin{array}{l}7 \\
(10.3 \%)\end{array}$ & & & \\
\hline $\begin{array}{l}\text { Prominence in the region of } \\
\text { the talonavicular joint }\end{array}$ & & & & & & $0.71(0.23,2.19)$ & $1.22(0.29,5.10)$ & 0.74 \\
\hline Right foot & - & $\begin{array}{l}2 \\
(2.9 \%)\end{array}$ & $\begin{array}{l}25 \\
(36.8 \%)\end{array}$ & $\begin{array}{l}31 \\
(45.6 \%)\end{array}$ & $\begin{array}{l}10 \\
(14.7 \%)\end{array}$ & & & \\
\hline Left foot & - & 1 & 29 & 28 & 10 & & & \\
\hline
\end{tabular}




\begin{tabular}{|c|c|c|c|c|c|c|c|c|}
\hline & & $(1.5 \%)$ & $(42.6 \%)$ & $(41.2 \%)$ & $(14.7 \%)$ & & & \\
\hline $\begin{array}{l}\text { Congruence of the medial } \\
\text { longitudinal arch }\end{array}$ & & & & & & $2.18(0.69,6.86)$ & $2.38(0.59,9.66)$ & 0.34 \\
\hline Right foot & - & - & $\begin{array}{l}26 \\
(38.2 \%)\end{array}$ & $\begin{array}{l}28 \\
(41.2 \%)\end{array}$ & $\begin{array}{l}14 \\
(20.6 \%)\end{array}$ & & & \\
\hline Left foot & - & - & $\begin{array}{l}30 \\
(44.1 \%)\end{array}$ & $\begin{array}{l}25 \\
(36.8 \%)\end{array}$ & $\begin{array}{l}13 \\
(19.1 \%)\end{array}$ & & & \\
\hline $\begin{array}{l}\text { Abduction/adduction of the } \\
\text { forefoot on the rear foot }\end{array}$ & & & & & & $0.68(0.23,2.02)$ & $0.80(0.19,3.42)$ & 0.79 \\
\hline Right foot & - & $\begin{array}{l}1 \\
(1.5 \%)\end{array}$ & $\begin{array}{l}26 \\
(38.2 \%)\end{array}$ & $\begin{array}{l}29 \\
(42.6 \%)\end{array}$ & $\begin{array}{l}12 \\
(17.6 \%)\end{array}$ & & & \\
\hline Left foot & - & $\begin{array}{l}1 \\
(1.5 \%)\end{array}$ & $\begin{array}{l}26 \\
(38.2 \%)\end{array}$ & $\begin{array}{l}28 \\
(41.2 \%)\end{array}$ & $\begin{array}{l}13 \\
(19.1 \%)\end{array}$ & & & \\
\hline
\end{tabular}

Afterward, at the end of one competition season and participating in games over 6 months, they were followed and reports of any injuries at the ankle during this period were obtained by taking history and examination.

\subsection{Statistical Analysis}

For continuous variables, values were reported as mean, Standard deviation, median and range (minimum, maximum) and categorical data were expressed as the number (percentage). The occurrence of an ankle sprain in the follow-up period was considered as a binary response with two possible outcomes (presence or absence of ankle sprain). The predictor variables included gender, age, height, weight, BMI, duration of professional exercise, dominant foot, history of previous ankle sprain and FPI score. To examine the association between the response variable and predictor variables, univariate logistic regression models were applied using generalized estimating equations (GEE) method to account for the correlation between right and left feet in the same subject. Statistical analysis was performed using the statistical software SPSS 16.0.0. (SPSS Inc. Chicago, IL, U.S.A.). P-values less than 0.05 were considered statistically significant.

\section{Result}

This study is comprised of 68 subjects (136 feet). Table 2 shows the characteristics of the participants.

Table 2. Characteristics of Participants $(\mathrm{n}=68)$

\begin{tabular}{ll}
\hline Gender, no. (\%) & $39(57.4 \%)$ \\
\hline Female & $29(42.6 \%)$ \\
Male & $22.06 \pm 3.62 ; 22(13,36)$ \\
Age, years & $167.82 \pm 9.53 ; 166(145,188)$ \\
Height, cm & $61.56 \pm 10.92 ; 59.5(41,87)$ \\
Weight, kg & $21.74 \pm 2.60 ; 21.53(16.41,32.35)$ \\
BMI & $4.19 \pm 2.47 ; 4(1,10)$ \\
Duration of professional exercise & \\
Dominant foot, no.(\%) & $61(89.7 \%)$ \\
Right foot & $7(10.3 \%)$ \\
Left foot & \\
Positive history of ankle sprain, no. (\%) & $40(58.8 \%)$ \\
Right foot & $29(42.6 \%)$ \\
Left foot & \\
FPI score & $4.90 \pm 2.88 ; 4.5(-1,12)$ \\
Right foot & $4.72 \pm 3.08 ; 4.5(-3,12)$ \\
Left foot & \\
Occurrence of new ankle sprain & $12(17.6 \%)$ \\
Right foot & $11(16.2 \%)$ \\
Left foot &
\end{tabular}


Data are expressed as $\{$ mean $\pm \mathrm{SD}$; median (min, $\max )\}$, unless otherwise stated.

Abbreviations: BMI, body mass index (calculated as weight in kilograms divided by height in meters squared); FPI, Foot Posture Index.

Table 3. Correlation between variables and occurrence of new ankle sprain

\begin{tabular}{lll}
\hline Variables & Unadjusted OR $(95 \%$ CI for OR) & P-value \\
\hline Foot (right foot vs. left foot) & $1.11(0.48,2.59)$ & 0.81 \\
Gender (female vs. male) & $0.41(0.16,1.04)$ & 0.06 \\
Age & $1.08(0.97,1.19)$ & 0.16 \\
Height & $1.03(0.98,1.08)$ & 0.21 \\
Weight & $1.02(0.98,1.06)$ & 0.29 \\
BMI & $1.03(0.88,1.21)$ & 0.68 \\
Duration of professional exercise & $1.07(0.92,1.23)$ & 0.39 \\
Dominant foot (right foot vs. left foot) & $1.25(0.14,10.92)$ & 0.84 \\
History of previous ankle sprain (present vs. absent) & $6.02(1.93,18.84)$ & 0.002 \\
FPI score & $1.05(0.88,1.25)$ & 0.60
\end{tabular}

Abbreviations: OR: Odds ratio; 95\% CI: 95\% confidence interval; BMI, body mass index (calculated as weight in kilograms divided by height in meters squared); FPI, Foot Posture Index

* Unadjusted OR (95\% CI for OR) obtained from univariate logistic regression models using generalized estimating equations (GEE) method to account for the correlation between right and left feet in the same subject. In the fitted models, the occurrence of a new ankle sprain in the follow-up period was considered as a binary outcome (Yes/no).

Table 3 presents the unadjusted odds ratio (with 95\% CI for OR) of univariate logistic regression models obtained by GEE approach.

Table 4. Association between FPI score and occurrence of new ankle sprain

\begin{tabular}{lll}
\hline & mean $\pm \mathrm{SD} ;$ median $(\min , \mathrm{max})$ & OR $(95 \%$ CI for OR) \\
\hline FPI score & & $1.05(0.88,1.25)$ \\
Right foot & $4.90 \pm 2.88 ; 4.5(-1,12)$ & \\
Left foot & $4.72 \pm 3.08 ; 4.5(-3,12)$ & \\
\hline
\end{tabular}

According to our findings, there was no significant association between FPI score and the log odds of occurrence of ankle sprain ( $\mathrm{p}=0.60$, Table 4). Also, no association was existed between gender, age, height, weight, BMI, duration of professional exercise, dominant foot and the log odds of occurrence of ankle sprain (Table 3).

In this study, the history of previous ankle sprain was the only significant predictor of the occurrence of ankle sprain in the follow-up period. Participants with the positive history of previous ankle sprain were at higher risk of developing new ankle sprain ( $\mathrm{OR}=6.02,95 \% \mathrm{CI}$ : $(1.93,18.84), \mathrm{p}=0.002)$.

\section{Discussion}

Diverse Foot Postures are associated with alteration in biomechanics, kinetics and foot function that may lead to injury.

From Joint Kinematic point of view, the bone morphology of the talus, explains the potential instability in movement; therefore, combining rotation and slide, can be modulated by the talar morphology, explaining the occurrence of at-risk ankles. On the other, the delay in muscle activity could be a major component in ankle instability.

Regarding the incidence of structural abnormality in foot of soccer players, we choose our target group from 
premier league, although abnormal Structure is not considered an obstacle in competition and somehow it deemed an advantage in some soccer maneuvers, we suppose that deviation in FPI score may lead to injury.

Static morphologic problems induce an unstable dynamic movement on weight-bearing. Varus of hindfoot results in excessive pressure on the lateral edge of the foot and postural imbalance in mono podal weight-bearing. It is responsible for excessive tension of the Proneals muscles, with most often a loss of the myotatic reflex.

The peroneal muscles are active before initial foot contact during stair descent and landing after a jump. If the peroneal muscles are to protect against unexpected inversion of the rearfoot, preparatory muscle activation before foot contact with the ground is necessary.

An acceptable assumption is that subjects with pronated or supinated feet have slower proneal reaction time, meanwhile chronic ankle instability is associated with latency in reaction time of ankle evertor muscles (Denyer, Hewitt, \& Mitchell, 2013; Mitchell, Dyson, Hale, \& Abraham, 2008; Willems et al., 2005). Therefore we anticipated that an association may exist between deviation of normal score of FPI and incidence of ankle injury but we could not find any correlation.

In this study, the history of previous ankle sprain was the only significant predictor of the occurrence of ankle sprain in the follow-up period. It implicates that Functional ankle instability alongside with structural ankle injury may account for further injury.

The mechanism of recurrent ankle injury is the same of initial acute ankle sprains; however, adverse functional and Mechanical changes predispose individuals to recurrent sprains. Impaired Proprioception, Neuromuscular-Firing Patterns Deficit, Poor Postural Control are the main contributors to functional instability.

In accordance with researches of Hagglund, Fulton and Malliaroplous, previous injury is identified as the most important risk factor for re- injury in ankle. Deficit in neuromuscular conditioning, altered proprioception, Dynamic biomechanically errors, incorrect movement pattern and psychologically factors are the plausible issues for the recurrence of injury (Fulton et al., 2014; Hägglund, Waldén, \& Ekstrand, 2006; Malliaropoulos, Ntessalen, Papacostas, Longo, \& Maffulli, 2009).

Along with FPI, lack of probable link with abnormal score and ankle injury in our study casts a doubt on biomechanical hypothesis. One of the most important obstacles in our study was paucity of supinated foot in participant so evaluation of relationship between supinated feet and ankle sprain was not applicable.

In Cain et al study, a significant correlation was found between under-pronated or supinated feet and foot/ankle overuse injury in adolescent Futsal player, meanwhile under-pronated to supinated foot type was associated with higher Futsal play ability (Cain, Nicholson, Adams, \& Burns, 2007). Similar with our investigation in population study, sample size and method, the finding are not consistent with our result. The difference may drive from our limitation in finding participants with supinated foot type and ethnical consideration.

Neilsen et al reported that there is no association between foot pronation and increased risk of injury in novice runners (Nielsen et al., 2014). This prospective cohort investigation is consistent with our finding.

From biomechanical point of view, foot structure may affect neuromuscular control of ankle. Thus, postural stability and proprioception have been altered in supinated and pronated feet. This correlation could be demonstrated by conducting dynamic assessment of foot/ankle. Since our study evaluated static measurement of feet, it may not account for showing the neuromuscular alteration in non-neutral feet. Conducting dynamic investigation in future could shed a light on other aspects of correlation between foot anatomy and function.

It is important to prospectively identify modifiable and constant risk factors so that strategies may be adapted to minimize injury occurrence. If risk for injury can be identified prior to the training season interventions such as custom orthotics, tailored specific training or shoe wear prescription may be recommended to the athletes to help minimize potential injuries and time lost from sport participation.

\section{Conclusion}

There was no significant association between FPI score and occurrence of ankle sprain. Participants with the positive history of previous ankle sprain were at higher risk of developing new ankle sprain.

\section{Acknowledgements}

We gratefully acknowledge Iranian Federation of Indoor Football, Tehran Futsal league and Ghazvin Futsal league for their irreplaceable assistance.

\section{Conflict of Interest}

The authors declare that there is no conflict of interests regarding the publication of this paper. 


\section{References}

Beynnon, B. D., Murphy, D. F., \& Alosa, D. M. (2002). Predictive factors for lateral ankle sprains: A literature review. Journal of Athletic Training, 37(4), 376.

Burns, J., Keenan, A.-M., \& Redmond, A. (2005). Foot type and overuse injury in triathletes. Journal of the American Podiatric Medical Association, 95(3), 235-241. http://dx.doi.org/10.7547/0950235

Cain, L. E., Nicholson, L. L., Adams, R. D., \& Burns, J. (2007). Foot morphology and foot/ankle injury in indoor football. Journal of Science and Medicine in sport, 10(5), 311-319. http://dx.doi.org/10.1016/j.jsams.2006. 07.012

Canale, S. T., \& Beaty, J. H. (2008). Campbell's Operative Orthopaedics (11th ed. Vol. 3). MOSBY.

Chinn, L., \& Hertel, J. (2010). Rehabilitation of ankle and foot injuries in athletes. Clinics in sports medicine, 29(1), 157-167. http://dx.doi.org/10.1016/j.csm.2009.09.006

Cote, K. P., Brunet, M. E., II, B. M. G., \& Shultz, S. J. (2005). Effects of pronated and supinated foot postures on static and dynamic postural stability. Journal of Athletic Training, 40(1), 41.

Denyer, J. R., Hewitt, N. L., \& Mitchell, A. C. (2013). Foot structure and muscle reaction time to a simulated ankle sprain. Journal of Athletic Training, 48(3), 326. http://dx.doi.org/10.4085/1062-6050-48.2.15

DiGiovanni, C. W., \& Greisberg, J. (2007). Foot and ankle: Core knowledge in orthopaedics: Elsevier Health Sciences.

Fulton, J., Wright, K., Kelly, M., Zebrosky, B., Zanis, M., Drvol, C., \& Butler, R. (2014). Injury risk is altered by previous injury: A systematic review of the literature and presentation of causative neuromuscular factors. International Journal of Sports Physical Therapy, 9(5), 583.

Hägglund, M., Waldén, M., \& Ekstrand, J. (2006). Previous injury as a risk factor for injury in elite football: A prospective study over two consecutive seasons. British Journal of Sports Medicine, 40(9), 767-772. http://dx.doi.org/10.1136/bjsm.2006.026609

Hertel, J. (2000). Functional instability following lateral ankle sprain. Sports Medicine, 29(5), 361-371. http://dx.doi.org/10.2165/00007256-200029050-00005

Kaufman, K. R., Brodine, S. K., Shaffer, R. A., Johnson, C. W., \& Cullison, T. R. (1999). The effect of foot structure and range of motion on musculoskeletal overuse injuries. The American Journal of Sports Medicine, 27(5), 585-593.

Malliaropoulos, N., Ntessalen, M., Papacostas, E., Longo, U. G., \& Maffulli, N. (2009). Reinjury after acute lateral ankle sprains in elite track and field athletes. The American Journal of Sports Medicine, 37(9), 1755-1761. http://dx.doi.org/10.1177/0363546509338107

McManus, A., Stevenson, M., Finch, C. F., Elliott, B., Hamer, P., Lower, A., \& Bulsara, M. (2004). Incidence and risk factors for injury in non-elite Australian Football. Journal of Science and Medicine in sport, 7(3), 384-391. http://dx.doi.org/10.1016/S1440-2440(04)80033-1

Mei-Dan, O., Kahn, G., Zeev, A., Rubin, A., Constantini, N., Even, A., ... Mann, G. (2005). The medial longitudinal arch as a possible risk factor for ankle sprains: A prospective study in 83 female infantry recruits. Foot \& ankle international, 26(2), 180-183.

Mitchell, A., Dyson, R., Hale, T., \& Abraham, C. (2008). Biomechanics of ankle instability. Part 1: Reaction time to simulated ankle sprain. Medicine + Science in Sports + Exercise, 40(8), 1515.

Morrison, K. E., \& Kaminski, T. W. (2007). Foot characteristics in association with inversion ankle injury. Journal of Athletic Training, 42(1), 135.

Nielsen, R. O., Buist, I., Parner, E. T., Nohr, E. A., Sørensen, H., Lind, M., \& Rasmussen, S. (2014). Foot pronation is not associated with increased injury risk in novice runners wearing a neutral shoe: A 1-year prospective cohort study. British Journal of Sports Medicine, 48(6), 440-447. http://dx.doi.org/10.1136/ bjsports-2013-092202

Redmond, A. C., Crane, Y. Z., \& Menz, H. B. (2008). Normative values for the foot posture index. Journal of Foot and Ankle Research, 1(1), 6. http://dx.doi.org/10.1186/1757-1146-1-6

Redmond, A. C., Crosbie, J., \& Ouvrier, R. A. (2006). Development and validation of a novel rating system for scoring standing foot posture: The Foot Posture Index. Clinical Biomechanics, 21(1), 89-98. http://dx.doi.org/10.1016/j.clinbiomech.2005.08.002 
Urguden, M., Kizilay, F., Sekban, H., Samanci, N., Ozkaynak, S., \& Ozdemir, H. (2011). Evaluation of the lateral instability of the ankle by inversion simulation device and assessment of the rehabilitation program. Acta orthopaedica et traumatologica turcica, 44(5), 365-377. http://dx.doi.org/10.3944/AOTT.2010.2248

Willems, T. M., Witvrouw, E., Delbaere, K., Mahieu, N., De Bourdeaudhuij, I., \& De Clercq, D. (2005). Intrinsic risk factors for inversion ankle sprains in male subjects a prospective study. The American Journal of Sports Medicine, 33(3), 415-423. http://dx.doi.org/10.1177/0363546504268137

Willems, T., Witvrouw, E., Delbaere, K., De Cock, A., \& De Clercq, D. (2005). Relationship between gait biomechanics and inversion sprains: A prospective study of risk factors. Gait \& posture, 21(4), 379-387. http://dx.doi.org/10.1016/j.gaitpost.2004.04.002

\section{Copyrights}

Copyright for this article is retained by the author(s), with first publication rights granted to the journal.

This is an open-access article distributed under the terms and conditions of the Creative Commons Attribution license (http://creativecommons.org/licenses/by/3.0/). 